\title{
A CONSTRUÇÃO DAS PAISAGENS TURÍSTICAS NO VELHO CAMINHO DOS DIAMANTES ${ }^{1}$
}

\author{
THE CONSTRUCTION OF TOURIST LANDSCAPES IN THE DIAMOND PATH
}

Altamiro Sérgio Mol Bessa*

\begin{abstract}
RESUMO
Ao tentar retomar ocupações e traçados do passado, o turismo pode retomar, simultaneamente, (in)capacidades e conflitos presentes desde sempre nos lugares. Esta é a tese proposta neste trabalho. Para demonstrá-la, como objetos de estudo foram tomados dois núcleos históricos situados no antigo Caminho dos Diamantes, uma das três rotas que formavam as Estradas Reais: os distritos de Milho Verde e São Gonçalo. Estas localidades, grandes produtoras de diamantes nos séculos XVII e XVIII, ao final do período da mineração apresentavam paisagens distintas. Mantidas abandonadas por mais de um século, em função do esvaziamento econômico a que foi submetido todo o norte mineiro, estas localidades foram descobertas pelo turismo nas décadas finais do século XX. Os resultados desta pesquisa mostraram que o turismo em Milho Verde retomou o antigo Caminho dos Diamantes como condutor dos novos processos insustentáveis que se estabeleceram sobre a localidade. Em São Gonçalo, o tipo de turismo que se estabeleceu retomou o antigo Caminho como atrativo turístico, recuperando as capacidades que historicamente fizeram da localidade um lugar paisagisticamente qualificado. A construção metodológica desta pesquisa centrou-se na paisagem como principal categoria de percepção e análise dos fenômenos.
\end{abstract}

Palavras-chave: Paisagens turísticas. Construção de paisagens turísticas. História. Turismo. Caminho dos Diamantes.

\begin{abstract}
When retaking occupations and traces of the past, tourism can simultaneously retrieve (in)capacities and conflicts ever-present in the places. In order to demonstrate this thesis, was taken as objects of study two historical centers situated in the old Caminho dos Diamantes (Diamond Path), the districts of Milho Verde and São Gonçalo. The Caminho dos Diamantes is one of three routes that formed the Estrada Real (Royal Road). These localities, great producers of diamonds in the XVIlth and XVIIIth centuries, by the end of the mining period, presented distinct landscapes. These localities, forsaken for over a century as a result of the economic exhaustion forced upon the North of Minas Gerais, were rediscovered by tourism in the last decades of the XXth Century. The results of the research show that tourism in Milho Verde regained the old Diamond Path as a conductor of new unsustainable processes that had been established there. In São
\end{abstract}

Este artigo é resultado da tese de doutorado $\mathrm{A}$ construção das paisagens turísticas nos descaminhos da Estrada Real, defendida em 2011, no Programa de Pós-Graduação em Arquitetura e Urbanismo da Universidade de São Paulo - Área de Concentração Paisagem e Ambiente -, orientada pela professora doutora Maria Angela Faggin Pereira Leite, e de pesquisa financiada pelo Conselho Nacional de Desenvolvimento Científico e Tecnológico (CNPq).

* Arquiteto e urbanista formado pelo Instituto Metodista Izabela Hendrix, mestre em Turismo e Meio Ambiente pelo Centro Universitário Una, doutor em Arquitetura e Urbanismo pela Faculdade de Arquitetura e Urbanismo da Universidade de São Paulo (FAUUSP). Professor adjunto do Departamento de Urbanismo da Universidade Federal de Minas Gerais (UFMG). altamirobessa@gmail.com 
Gonçalo, the type of tourism established regained the old Path as a tourist attraction, restoring the potentialities that historically made the locality a place of qualified landscape. The methodological framework of this research has been centered on the landscape as the main category of perception and analysis of the phenomena.

Keywords: Tourist landscapes. Construction of tourist landscapes. History. Tourism. Diamond Path.

\section{INTRODUÇÃO}

O homem, ao longo da sua história, vem construindo sobre a natureza e com a natureza objetos que junto com as ações humanas acumulam-se ao longo do tempo, constituindo o patrimônio cultural da humanidade. Estas realizações culturais estão representadas nos assentamentos humanos, cuja qualidade ambiental diversa é uma medida de sustentabilidade que transcende a simples utilização racional dos recursos naturais. Muitos destes assentamentos são hoje apropriados pelo turismo, que termina por interferir na (in)sustentabilidade existente destes lugares quando busca torná-los mais sedutores para turistas, empresas e eventos. Às paisagens cabe o papel de revelar não só os ambientes resultantes como também as ideologias, os valores e as ações que presidiram suas construções e transformações em cada tempo histórico.

O estudo das paisagens primeiras do Brasil colônia mostra que a empresa mercantil portuguesa ocupou por mais de dois séculos as áreas litorâneas e só descobriu o interior do território brasileiro quando ali foram encontradas as primeiras minas de ouro. Entre os núcleos mineradores que surgiram foram construídos caminhos que, no final do século XVII, tornaram-se oficiais: as chamadas Estradas Reais.

Estas Estradas passavam por dois importantes núcleos mineradores incrustados nas terras altas da serra do Espinhaço e nas proximidades do rio Jequitinhonha, no norte do atual Estado de Minas Gerais: a Vila do Príncipe, hoje cidade do Serro, e - Arraial do Tejuco, agora Diamantina. Foi no caminho entre estas duas localidades que, em 1720, foram descobertos os diamantes, que provocaram a vinda de levas de aventureiros. Para controlar esta ocupação e a produção de diamantes, Portugal demarcou a região, criando, em 1734, o distrito Diamantino. Toda a área demarcada, a partir de então, tornou-se um enclave rigidamente controlado, permanecendo isolado até a sua extinção em 1882.

No distrito Diamantino, duas localidades tiveram importância estratégica. A primeira, Milho Verde, por ocupar posição bem no meio do Caminho dos Diamantes, no alto de um platô, era entreposto tropeiro e sede do quartel, detendo as poucas terras férteis do distrito. Por esta razão tornou-se fornecedora de gêneros alimentícios para toda uma região. A segunda, São Gonçalo do Rio das Pedras, ocupando um fundo de vale cheio de regatos mineríferos, chegou a ser sede da Intendência, órgão responsável pela administração do distrito.

As duas localidades passaram pelo período diamantino de formas marcadamente diferenciadas. Embora muito próximas, distando aproximadamente 5 quilômetros uma da outra, Milho Verde e São Gonçalo, ao fim do ciclo da mineração, tinham 
paisagens bem distintas. As paisagens de Milho Verde revelavam um núcleo urbano degradado, economia enfraquecida, baixos indicadores de qualidade de vida, concentração de terras, pecuária extensiva e a maioria dos habitantes ocupada em atividades de subsistência. Já São Gonçalo emergiu do período diamantino com paisagens predominantemente mais qualificadas, caracterizadas pela ocupação urbana, pela boa qualidade ambiental ${ }^{2}$, com a população sobrevivendo de outras atividades produtivas, pelos cursos d'água preservados e pelo ambiente rural, que mantinha quase intactos os campos de cerrado e os fetos de mata atlântica, dentre outros aspectos positivos.

Ambas as localidades permaneceram por mais de um século com poucas modificações no quadro de suas paisagens, quando foram redescobertas, no final dos anos 1970, pelo turismo. Este foi impondo, paulatinamente, suas forças àqueles territórios, sequioso de atender a demanda cada dia mais crescente dos turistas pela exploração do patrimônio natural e cultural das localidades. $\bigcirc$ turismo foi se apropriando da natureza, da arquitetura, das festas, das tradições, dos costumes locais, de tudo o que poderia transformar-se em mercadorias colocadas para consumo. Em Milho Verde, os turistas e adventícios ${ }^{3}$ que chegavam buscavam usufruir do patrimônio natural cachoeiras, piscinas naturais, a bela vista que de lá se tem de um vasto planalto - e da possibilidade de vivenciar experiências de uma vida alternativa, mais livre, bem ao estilo dos movimentos da contracultura que surgiram a partir da segunda metade do século XX. Os que chegavam a São Gonçalo, por sua vez, buscavam a tranquilidade e as possibilidades de experimentar o cotidiano e a qualidade dos espaços livres e edificados que o "grupo romântico de um conjunto de casas", nas palavras do viajante inglês John Mawe (1944), oferecia.

Na década de 1990, um projeto turístico soma-se ao turismo que vinha se instalando nas duas localidades. Trata-se de um projeto do governo do Estado de Minas Gerais e da Federação das Indústrias do Estado de Minas Gerais (FIEMG), denominado Projeto Estrada Real. Desta maneira, as forças já incidentes do turismo em Milho Verde e São Gonçalo são acrescidas de novas, impostas por este projeto, ou, ao menos, pelos seus discursos.

A aparente percepção de que o turismo estava produzindo em Milho Verde, a exemplo do passado, novos processos insustentáveis - e, em São Gonçalo, paisagens como as antigas, tendendo à sustentabilidade - forneceu a este pesquisador, estudioso do fenômeno turístico e de suas manifestações nos territórios, o argumento central da tese: o turismo, ao tentar retomar ocupações e traçados do passado,

2 O conceito de qualidade ambiental foi desenvolvido pelo autor em capítulo específico da tese da qual se origina este artigo, e refere-se ao conjunto de indicadores que avaliam se na localidade há um uso racional e equilibrado dos recursos naturais, se as infraestruturas urbanas são funcionais e implantadas sem impactos ambientais negativos, se os equipamentos públicos são eficientes e se o sistema de espaços livres se constitui em espaço privilegiado para a constituição da esfera da vida pública.

3 Termo utilizado pela literatura do turismo para designar aqueles que não nasceram no lugar e para ele se mudaram, passando a viver ali. 
pode retomar, simultaneamente, (in)capacidades e conflitos presentes desde sempre nos lugares.

Para verificá-la, foram deslindadas as paisagens históricas de Milho Verde e São Gonçalo por pesquisas bibliográfica e documental. Já o quadro de suas paisagens contemporâneas foi construído com base nos dados da pesquisa de campo realizada nos meses de janeiro e fevereiro de 2010, em que se aplicou o método de análise visual e entrevistas. Para a análise visual foram divididos os distritos em setores, onde foram anotados, desenhados e fotografados os aspectos visuais constituidores das paisagens, as infraestruturas, os espaços livres, as tipologias arquitetônicas existentes e outros elementos significativos de cada rua. Os dados foram reunidos em acervo iconográfico e em 61 fichas, como a apresentada na figura 1, de seis setores em Milho Verde e cinco em São Gonçalo. As entrevistas foram aplicadas a 49 moradores (10\% da população urbana), um gestor do turismo e três informantes-chave em Milho Verde, e 79 pessoas (10\% da população urbana), um gestor do turismo e cinco informantes-chave em São Gonçalo.

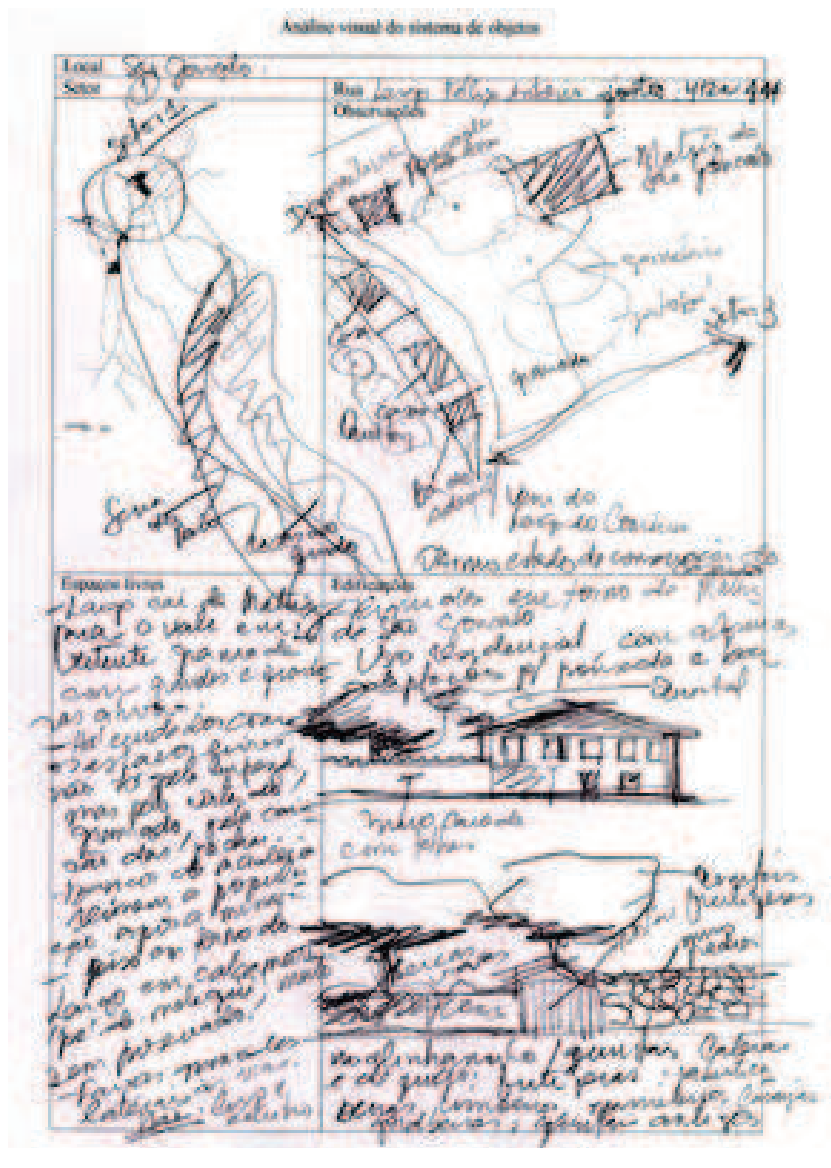

Figura 1 Ficha de análise visual aplicada na pesquisa de campo.

Fonte: Altamiro Sérgio Mol Bessa.

\section{PAISAGENS REVELADAS NO CAMINHO DOS DIAMANTES}

início da colonização portuguesa em terras brasileiras é marcado pela ocupação litorânea. A descoberta de ouro nas Minas Gerais altera este quadro: impele, de forma brusca, a ida do homem do litoral para o interior da colônia em busca de riqueza fácil. 
Os núcleos mineradores que vão surgindo se formam em torno das explorações do centro de Minas Gerais, numa faixa que se estende de sul a norte, da bacia do rio Grande às nascentes do Jequitinhonha, local onde se situam nossos objetos de estudo. Esta ocupação das minas provocou um processo de urbanização que logo deixou de ser a "coisa provisória", que caracterizou os primeiros assentamentos fundados pelos aventureiros, estimulando:

[...] o desenvolvimento de atividades mercantis necessárias ao abastecimento das áreas mineradoras, favorecendo a articulação não só entre regiões da capitania, como também com outras capitanias e com a própria metrópole. (MORAES, 2007, p. 64).

À medida que o processo de ocupação das áreas mineradoras se intensificava, surgia a necessidade da instalação de unidades político-administrativas ainda menores, mais próximas aos locais e aos acontecimentos: são criadas as comarcas. A comarca do Serro Frio, criada em 1720, desenha e define aquilo que hoje é a fronteira nordeste de Minas Gerais. A sede desta comarca foi estabelecida na Vila do Príncipe, criada em 1714, que atualmente é a cidade do Serro.

Antes de tornar-se conhecida pela produção de diamantes, a região do Serro Frio, tradução da palavra indígena "Ivituruí", que quer dizer "montanhas frias", já tinha ganhado fama pelas suas riquezas auríferas, descobertas nos últimos anos do século XVII. Com a descoberta dos diamantes, que data de pouco antes de 1720, a região do Serro Frio experimentou um aumento muito maior do fluxo migratório e do processo de ocupação do seu território.

Os diamantes eram facilmente encontrados nos rios e regatos da região e a produção cresceu tanto que o valor da pedra chegou a perder valor no mercado internacional. Para controlar e diminuir a produção, a metrópole demarca a região criando o Distrito Diamantino (1734).

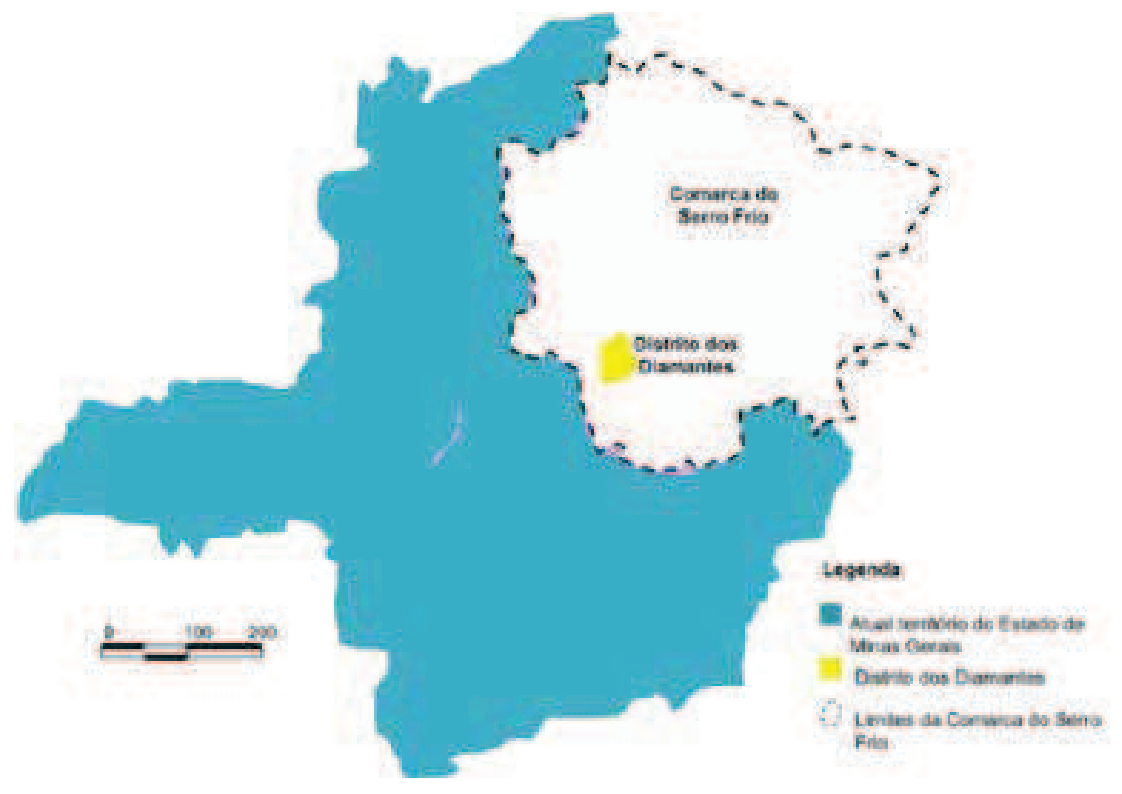

Figura 2 Localização da comarca do Serro Frio e do Distrito dos Diamantes no Estado de Minas Gerais. Elaborada por Sérgio Mol Bessa. Baseada em Moraes (2007, p. 69). 
A extração de diamantes no Brasil só era permitida dentro dos limites do Distrito Diamantino. No seu interior, estabeleceu-se uma série de postos e destacamentos militares - Milho Verde foi um deles - que permaneceram até a Independência. Exerciam controle sobre entrada e saída de víveres, ouro, diamantes, pessoas, animais ou qualquer outra coisa. Para escoar a produção do Distrito Diamantino, a metrópole portuguesa criou o Caminho dos Diamantes, uma das três rotas que formavam as Estradas Reais. É neste Caminho que ficavam os núcleos originais dos dois objetos de estudo deste trabalho: Milho Verde e São Gonçalo do Rio das Pedras.

\subsection{AS PAISAGENS DE MILHO VERDE}

Já nas primeiras décadas do século XVIII, a Coroa instala em Milho Verde um quartel e um posto fiscal, citados nos relatos dos viajantes John Mawe e Auguste de Saint-Hilaire, com o objetivo de controlar todas as entradas e saídas de víveres, diamantes e pessoas. Milho Verde torna-se, desta forma, o portão por onde entravam e saíam todas as coisas no Distrito dos Diamantes. "A posição, bem no meio da estrada que liga o Serro a Diamantina, no alto de um platô com vasta vista, era motivo de sobra para a escolha do lugar." (SANTIAGO, 2006, p.106).

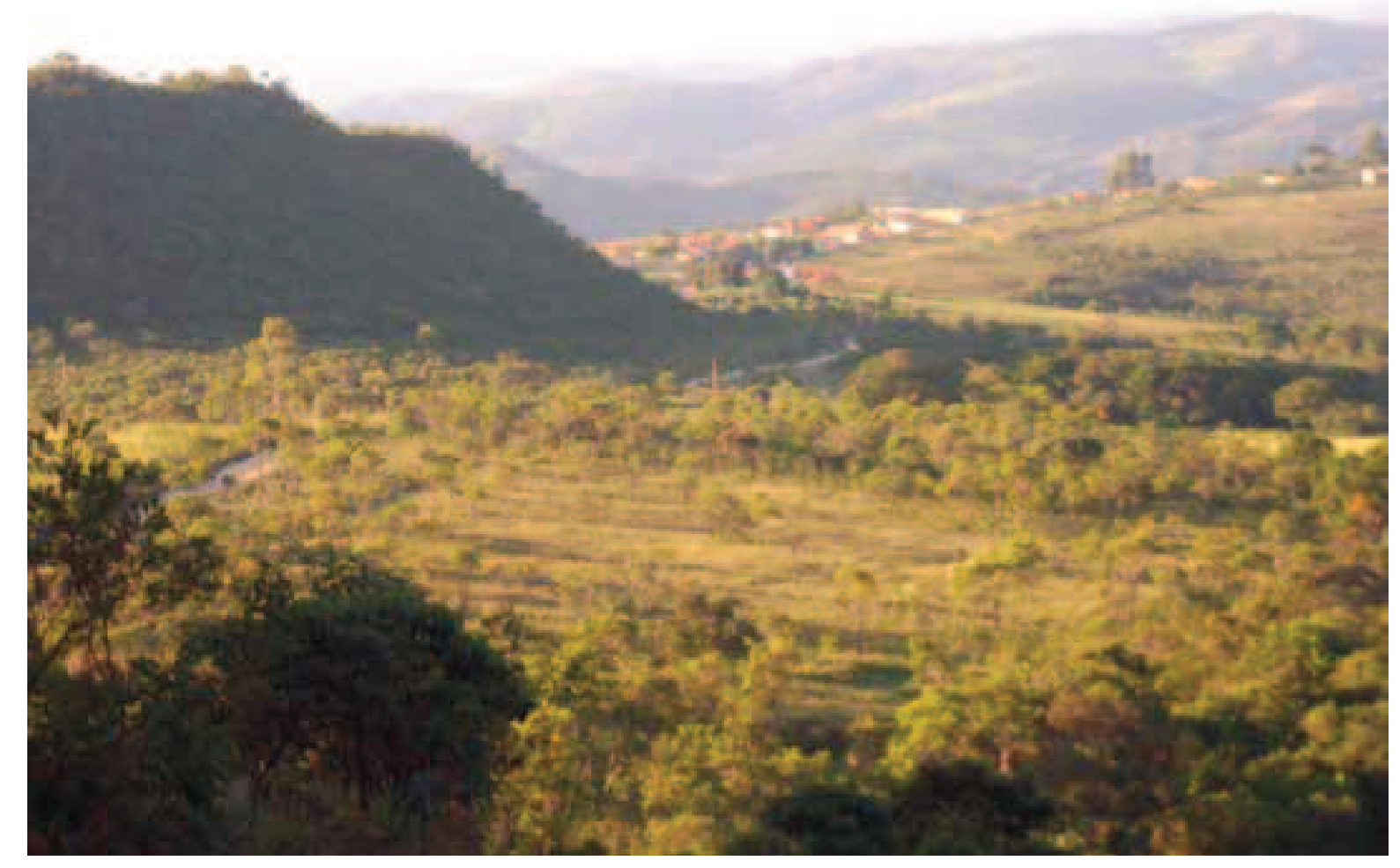

Figura 3 Vista do Distrito de Milho Verde.

Foto: Altamiro Sérgio Mol Bessa - 2010.

Esta posição geográfica privilegiada no Caminho dos Diamantes, a meio caminho das duas mais importantes localidades do Distrito dos Diamantes, permitiu que 
Milho Verde atuasse como entreposto tropeiro, polarizando o movimento de tropas das localidades do entorno de diversas regiões do país.

Outra característica que diferenciou Milho Verde das demais localidades do Distrito dos Diamantes foi a sua produção agrícola. A localidade era fornecedora de gêneros alimentícios para toda a região mineradora. As poucas terras férteis do Distrito situavam-se ali, e a população local, proibida de minerar, passou a ocupar-se da agricultura.

A necessidade de aumentar cada vez mais o tamanho das terras gerava um processo particular de estrutura agrária, próprio das regiões mineradoras, em que a acumulação de capital gerada pelos lucros da mineração propiciava a aquisição de grandes glebas. Em Milho Verde, este fato gerou a concentração de terras nas mãos daqueles que lucravam com a atividade mineradora. Além disto, os mesmos recursos que permitiam a aquisição de grandes propriedades rurais financiavam a formação da infraestrutura para a atividade comercial, que também ficava sob o domínio dos mesmos latifundiários e empreendedores da mineração.

Com o fim do ciclo do ouro e dos diamantes, a agricultura de subsistência, a criação de gado e a colheita de sempre-vivas, utilizadas no artesanato, passaram a ser a base da economia de Milho Verde durante quase todo o século XX (ARNDT, 2007). Porém, no final deste século, o turismo começa a surgir no Distrito.

"A efervescência turística hoje experimentada em Milho Verde tem talvez dez anos, embora certo turismo, digamos cult, existia desde os anos setenta." (SANTIAGO, 2006 , p. 114). No princípio, este movimento turístico assustou os moradores locais que "[...] venderam suas casas em Milho Verde e se mudaram para o Povoado de Capivari, aos pés do gigante Itambé, em busca de sossego." (SANTIAGO, 2006, p. 114).

Atualmente, a situação turística que se estabeleceu em Milho Verde, a pretexto de garantir maior liberdade ao turista na exploração das riquezas naturais do lugar, é resistente a qualquer controle. Atrai, com isto, muitos adventícios, que, seduzidos por esta "liberdade" de atuação, não só se aproveitam dela para viver uma vida alternativa, mas, também, para lucrar. Compram os melhores terrenos e casas das áreas centrais para nelas instalarem seus negócios, terminando por produzir uma excessiva valorização destas áreas. Os nativos, antigos residentes, vendem suas propriedades aproveitando-se do aumento do preço dos imóveis, que por muito tempo ficaram desvalorizados em função da estagnação econômica que perdurou desde a extinção do Distrito Diamantino. Depois de vendê-las, alguns migram para a periferia de MiIho Verde, provocando ali um processo de expansão territorial não planejado. Outros abandonam o Distrito, indo morar em outras localidades.

A figura 4 mostra a planta da localidade, com destaque para os espaços livres urbanos de uso público, nos quais acontecem as principais manifestações festivas e a concentração de turistas - e onde a população se reúne para conversar e para o lazer. Também são mostrados os principais logradouros, com destaque para a rua Direita, que atravessa longitudinalmente toda a localidade, os pontos de referência 
para a comunidade local e os turistas, e as manchas de mata atlântica que ainda permanecem na sede do Distrito.

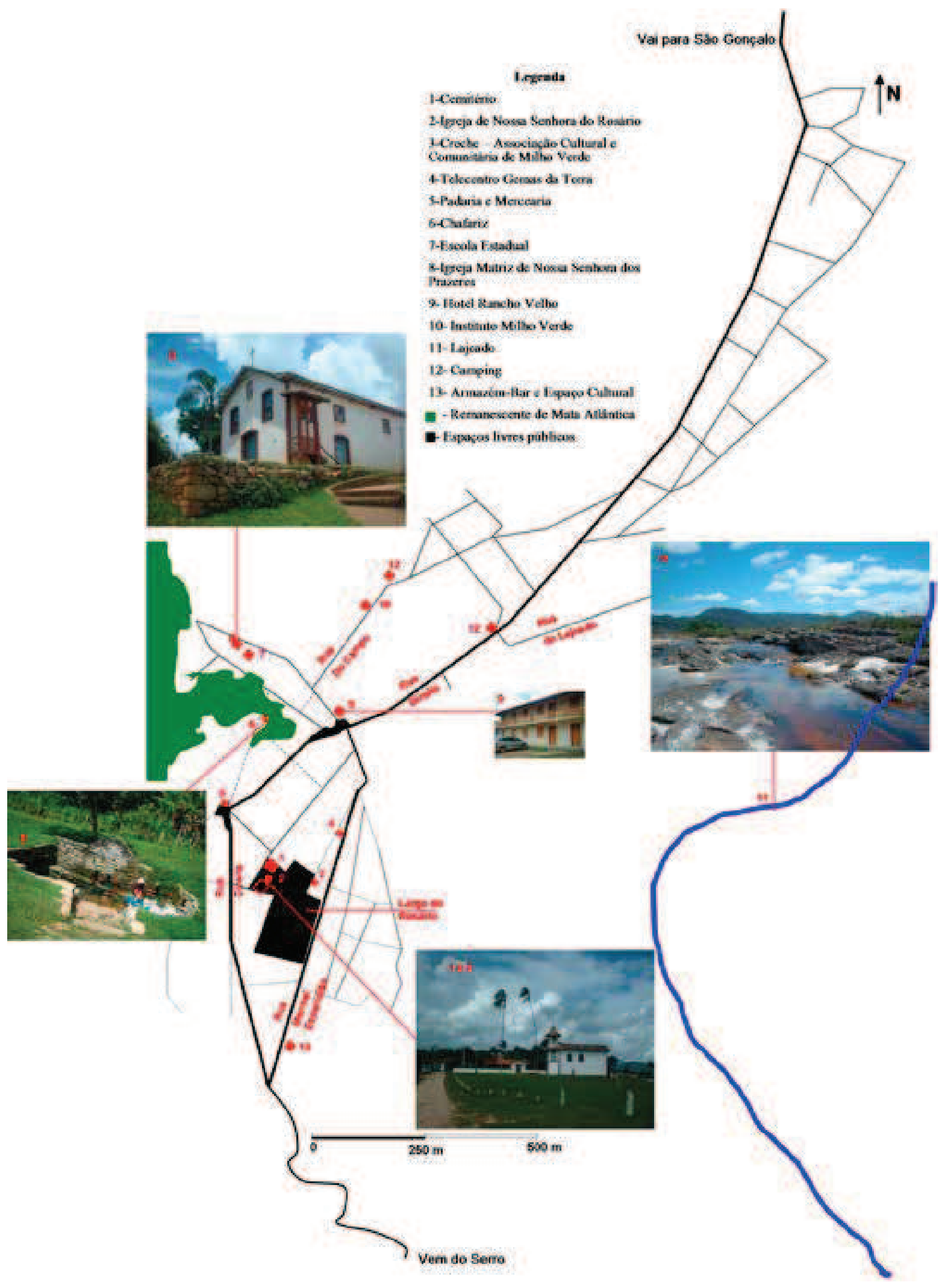

Figura 4 Planta de Milho Verde com seus principais atrativos turísticos.

Elaborada por Altamiro Sérgio Mol Bessa.

Baseada em pesquisas bibliográficas e de campo - 2010. 
Na Milho Verde contemporânea, submetida ao turismo, há ausência de articulação comunitária e predomina a inoperância do Estado em questões fundamentais, tais como saúde, saneamento e segurança pública. Na divisão social do trabalho prevalecem moradores sem qualificação, ocupados, nos períodos sem a presença do turismo, com a agricultura de subsistência, a construção civil e a prestação sazonal de serviços não especializados para o turismo nos feriados e férias escolares. Estas atividades, extremamente dependentes do movimento turístico, não geram capital suficiente para as pessoas estabelecerem o próprio negócio, melhorarem as próprias edificações e cuidarem adequadamente dos espaços livres do Distrito. As forças locais não conseguem se articular num sistema que reivindique ou promova melhorias nas infraestruturas urbanas e nas questões sociais.

Ausente, o poder público municipal não controla os processos de expansão da mancha urbana de Milho Verde, que têm se dado sobre áreas ambientalmente frágeis (figura 5), ignora a situação de abandono de parte do rico patrimônio histórico, como se pode notar pela figura 6, e não controla o uso e a ocupação do solo, o que tem resultado no fracionamento, na verticalização das edificações e diminuição dos quintais no núcleo colonial para ampliar a oferta de pousadas, casas de veraneio e de aluguel por temporada.
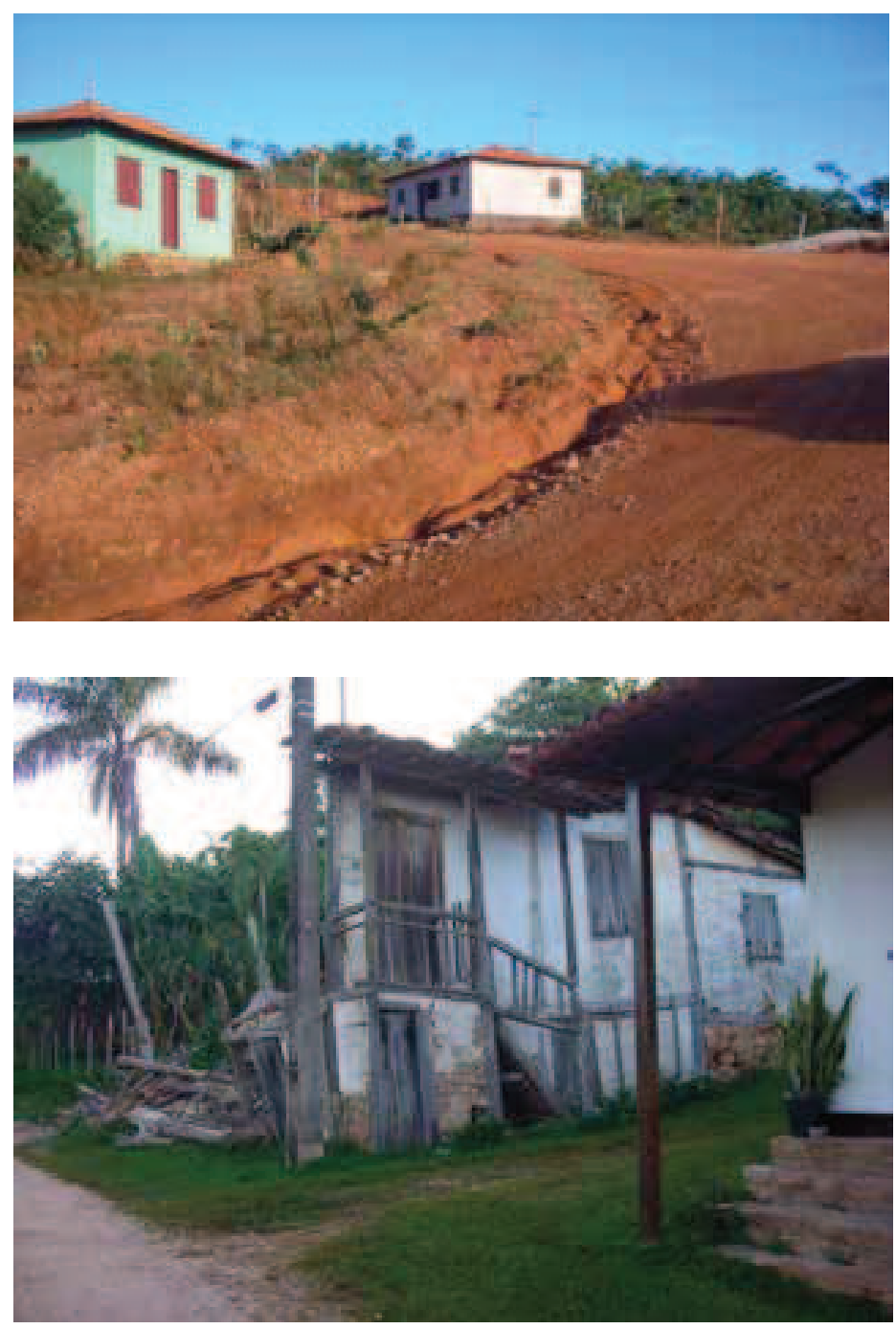

Figura 5 Ocupação de encostas em Milho Verde.

Foto: Altamiro Sérgio Mol Bessa 2010.

Figura 6 Ruínas de casarão em Milho Verde.

Foto: Altamiro Sérgio Mol Bessa 2010. 


\subsection{AS PAISAGENS DE SÃO GONÇALO DO RIO DAS PEDRAS}

Como a vizinha, Milho Verde, São Gonçalo do Rio das Pedras teve origens nos trabalhos de exploração do ouro no início do século XVIII. Em 1810, em visita ao local, Mawe (1944, p. 210-211) assim descreve São Gonçalo:

Ao fim do dia alcancei uma eminência, da qual avistei um grupo romântico de casas $^{4}$, semelhantes a um labirinto ou a uma cidade negra da África. Descemos a colina, e nos aproximamos do lugar, já noite fechada. Conduziram-me à casa maior que as outras; soube que estava em São Gonçalo, a primeira exploração de diamantes que se encontra no Serro Frio. Encontra-se, há algum tempo, em declínio e emprega cerca de duzentos negros. No dia seguinte, antes de deixar este local romântico, consagrei algum tempo ao exame de montões de detritos contíguos à exploração de diamantes. Tendo-me despedido do administrador, avancei por uma região montanhosa, estéril e fracamente habitada.

No século XIX, São Gonçalo chegou a ser a sede da intendência dos diamantes. Apesar de Mawe dizer que a mineração encontrava-se em declínio, ela duraria muito tempo ainda.

Os maiores vínculos da localidade sempre foram com Diamantina, acompanhando, inclusive, a reação das elites daquela cidade em relação ao declínio da mineração. Assim, instalaram-se no Distrito pequenas lapidações e oficinas de ourives, seguidas pela indústria do vinho (SANTIAGO, 2006).

Ainda hoje são produzidos na localidade vinhos de uvas, de jabuticaba, de laranja - produtos comercializados nas mercearias, nos bares, restaurantes e nas sedes de organizações comunitárias locais.

Além da lapidação e da vinicultura, São Gonçalo encontrou no artesanato com capim, na tapeçaria e na fabricação de doces de frutas (plantadas nos quintais das casas), alternativas ao declínio da mineração. Tais atividades, à época desta pesquisa, ocupavam considerável parcela da população local.

A menor vinculação das atividades econômicas com a agricultura, pela ausência de terras férteis, aliada à presença constante de estrangeiros ao longo de sua história e pela maior concentração da população na área urbana, fizeram com que em São Gonçalo não se consolidasse um poder oligárquico e tampouco um monopólio das atividades comerciais, como ocorreu em Milho Verde (ARDNT, 2007).

O Distrito de São Gonçalo "[...] não sofreu grandes mudanças nos últimos cento e cinquenta anos [...]", preservando seu casario e a beleza de seu meio ecológico (SANTIAGO, 2006, p. 115). Estes atributos passaram a atrair, em meados de 1960, um restrito e seleto grupo de intelectuais, que começaram a frequentar a localidade a partir de sua divulgação pelo cinema. Em 1965, Joaquim Pedro de Andrade filma em São Gonçalo o clássico do cinema novo, $O$ padre e a moça, baseado no poema homônimo de Carlos Drummond de Andrade.

$4 \quad$ Grifo nosso. 
Estes primeiros visitantes de São Gonçalo buscavam o descanso e o usufruto de uma arquitetura preservada "[...] da aparência de uma cidade feita de casas de bonecas. Ruas limpas, jardins e fachadas bem cuidados." (SANTIAGO, 2006, p. 116 ).

Na década de 1980, o alemão Martin Kuhne e sua esposa, alguns intelectuais, como o escritor Osvaldo França Júnior, e um grupo de moradores de São Gonçalo, iniciaram um processo de organização comunitária e de empoderar-se da comunidade local. Aos poucos, com apoio e recursos externos, principalmente de organizações não governamentais, como a alemã Amntena, trabalharam para a melhoria das condições de vida no local. Logo o Distrito passou a contar com posto de saúde e abastecimento de água proveniente de poço artesiano. A escola local, pequena e com apenas as quatro séries iniciais do ensino fundamental, foi ampliada, passando a oferecer todas as séries até o final do ensino médio. Fundaram também associações e organizações que ainda hoje têm forte presença nas paisagens locais.

A ação transformadora iniciada e conduzida por Martin é reconhecida por parte dos moradores entrevistados na pesquisa de campo: 36\% citam espontaneamente o alemão como o iniciador da transformação da comunidade. Atribuem a ele, também, a capacidade que os moradores hoje revelam de controlar e organizar as atividades turísticas, que começaram a se intensificar nos anos 1990.

Em São Gonçalo, ocorre um tipo de turismo bem diferente do que o existente em Milho Verde, mais adequado a pequenos núcleos coloniais, em que o turista, mais educado e informado, reconhece e valoriza o patrimônio cultural e utiliza-o preocupando-se com a sua preservação. Este tipo de turismo tem produzido nas paisagens de São Gonçalo mais resultados positivos do que negativos. $\bigcirc$ sistema de objetos das suas paisagens contemporâneas tende à sustentabilidade: a expansão urbana se dá sem a ocupação de áreas ambientalmente frágeis; não se viram desmembramentos de lotes em outros, menores; as edificações mantêm gabarito térreo, quintais e áreas livres, e as novas edificações acompanham este modelo; os nativos continuam a ocupar residências e possuir lojas em áreas centrais; as novas edificações, sejam de turismo de segunda residência, sejam para pousadas e outras infraestruturas do turismo, são implantadas em sua maioria a partir de projetos que respeitam a topografia e os recursos naturais e incorporam nos seus projetos paisagísticos as espécies nativas; os espaços livres recebem da própria comunidade cuidados que os conservam com boa qualidade paisagística; o rio que corta a localidade não recebe esgotos, e os remanescentes da mata atlântica mantêm-se aparentemente preservados. A figura 7 mostra a planta da localidade, com destaque para os espaços livres urbanos de uso público, os remanescentes de mata atlântica, o rio das Pedras, a cachoeira do Comércio e os principais edifícios e pontos de referência para a comunidade local e os turistas.

Na figura 8 vê-se um arruamento gramado, que leva ao largo da matriz de São Gonçalo, com destaque para os muros de pedras e as cercas-vivas que abrigam os quintais. A figura 9 mostra uma vista do largo da matriz com seu extenso gramado. A 
figura 10, um arruamento típico de São Gonçalo.

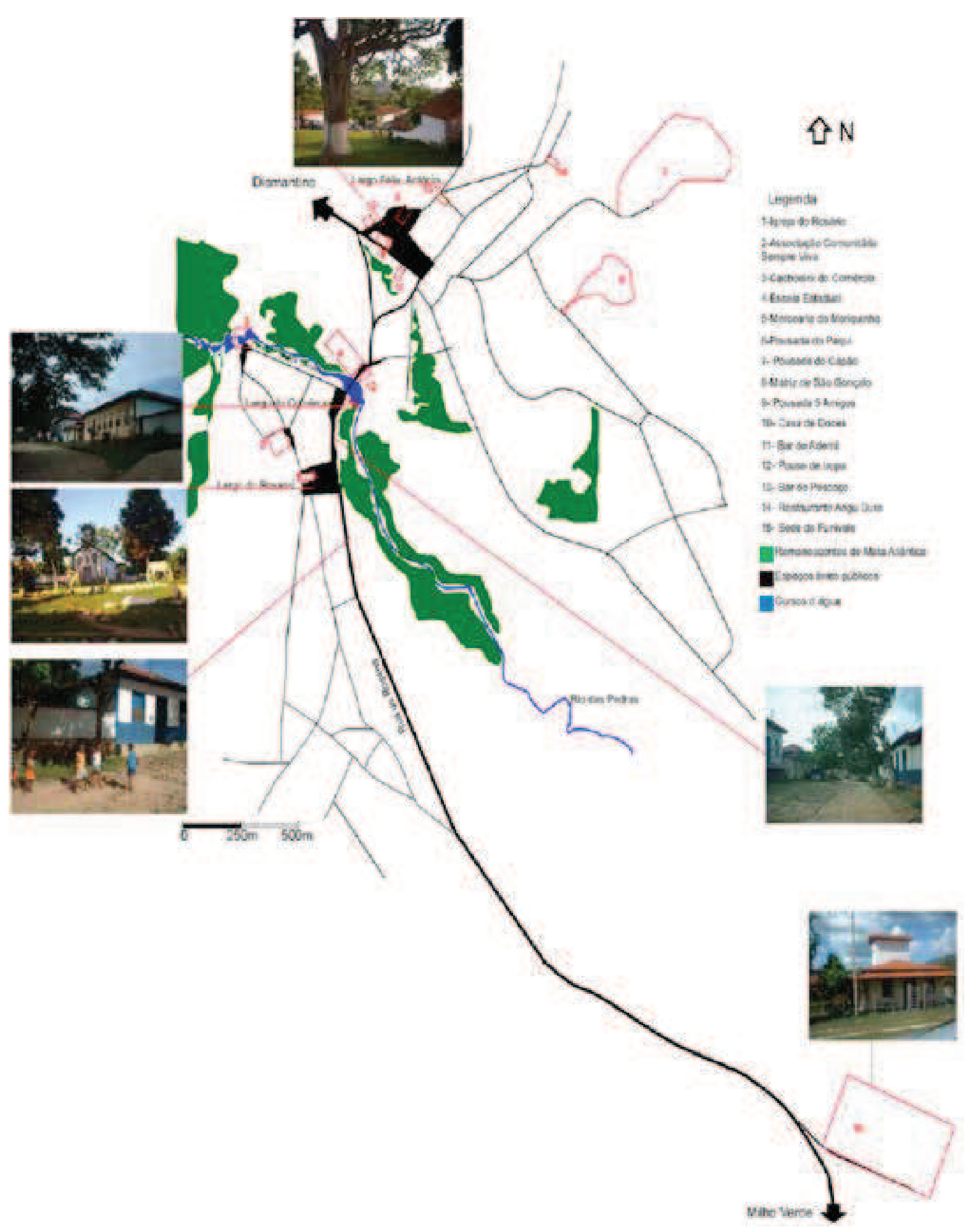

Figura 7 Planta de São Gonçalo do Rio das Pedras.

Elaborada por Altamiro Sérgio Mol Bessa.

Baseada em pesquisas bibliográficas e de campo - 2010. 


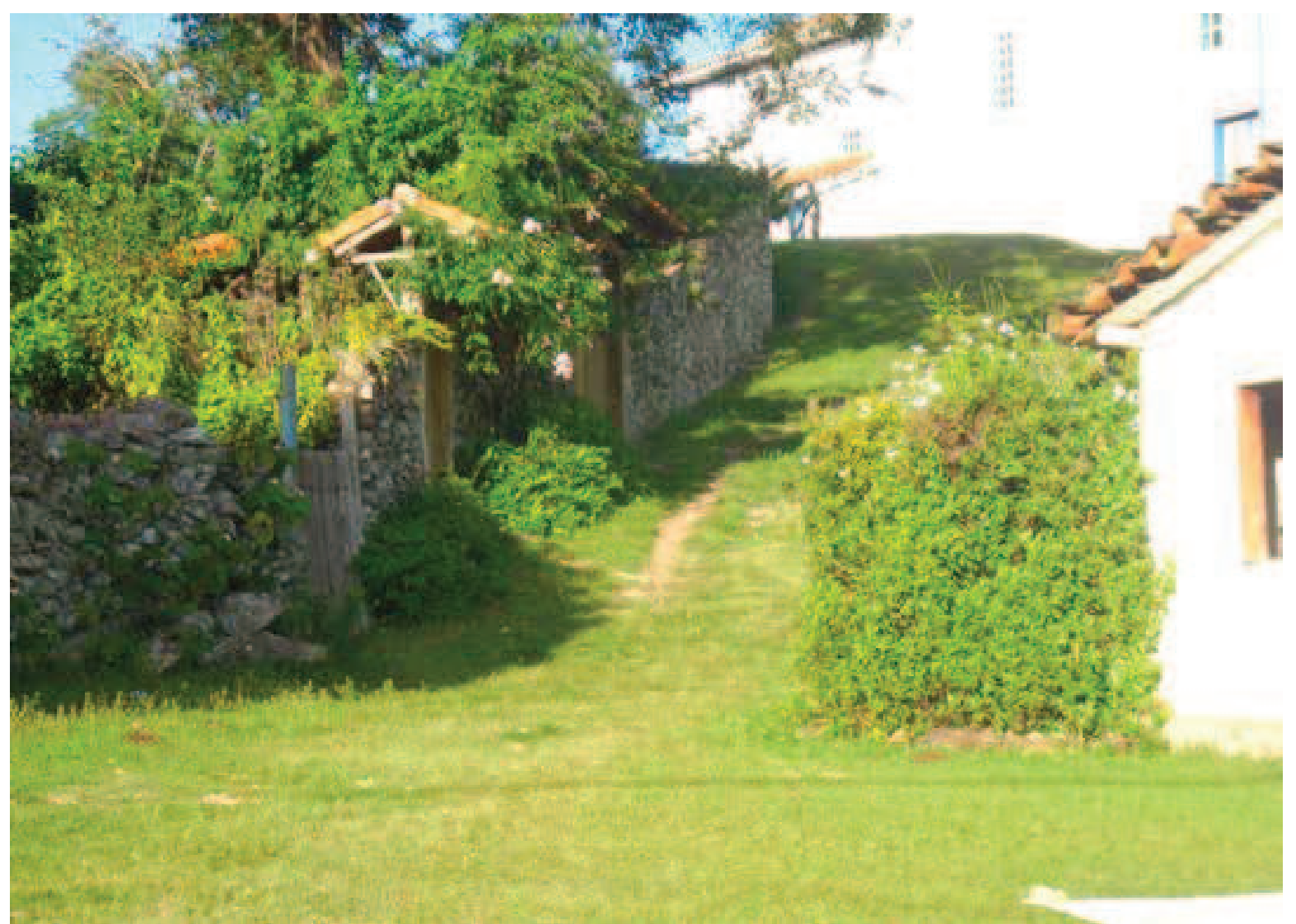

Figura 8 Muro de pedras e cercas-vivas em São Gonçalo.

Foto: Altamiro Sérgio Mol Bessa - 2010.

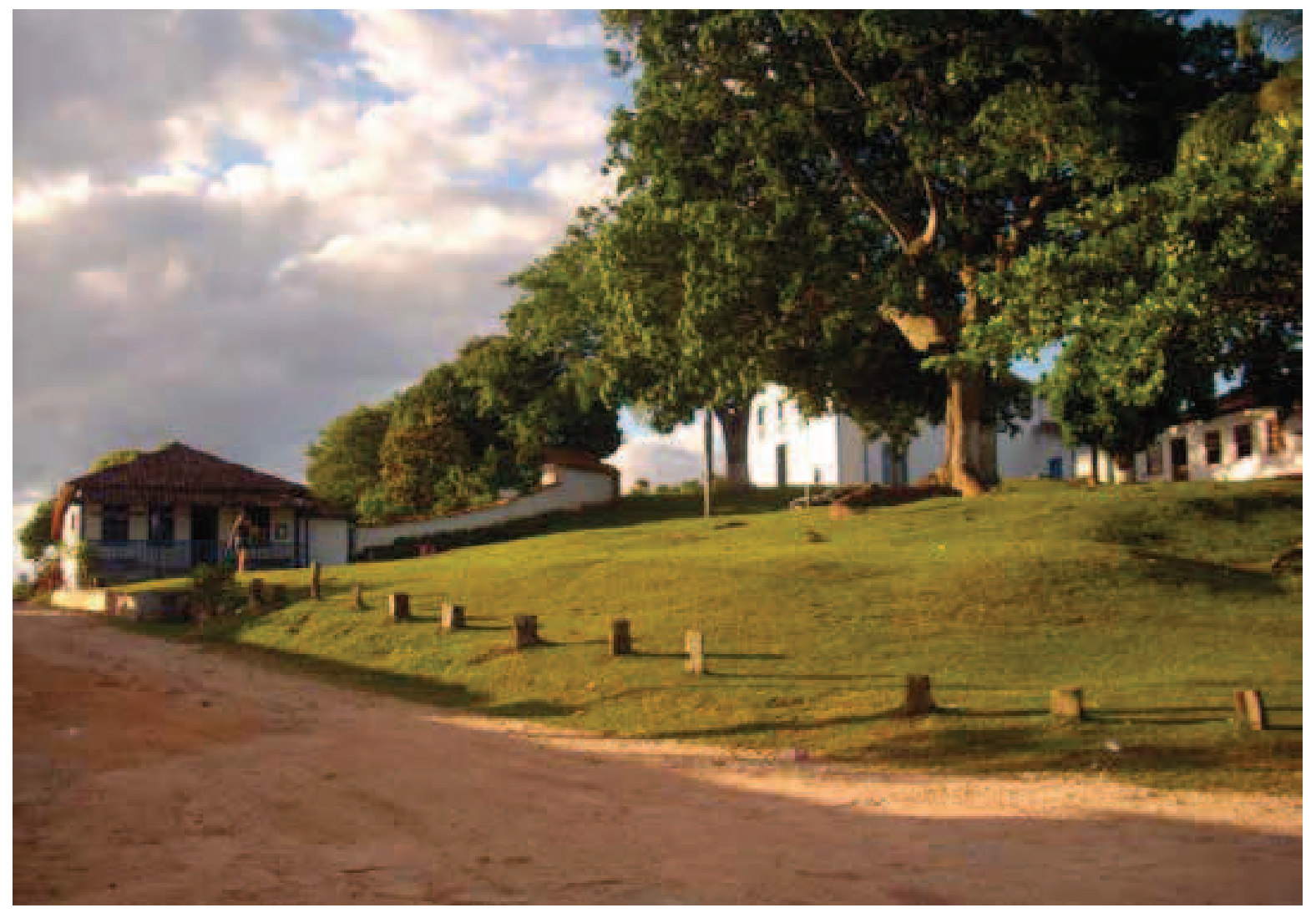

Figura 9 Vista do Largo da Matriz de São Gonçalo. Foto: Altamiro Sérgio Mol Bessa - 2010. 


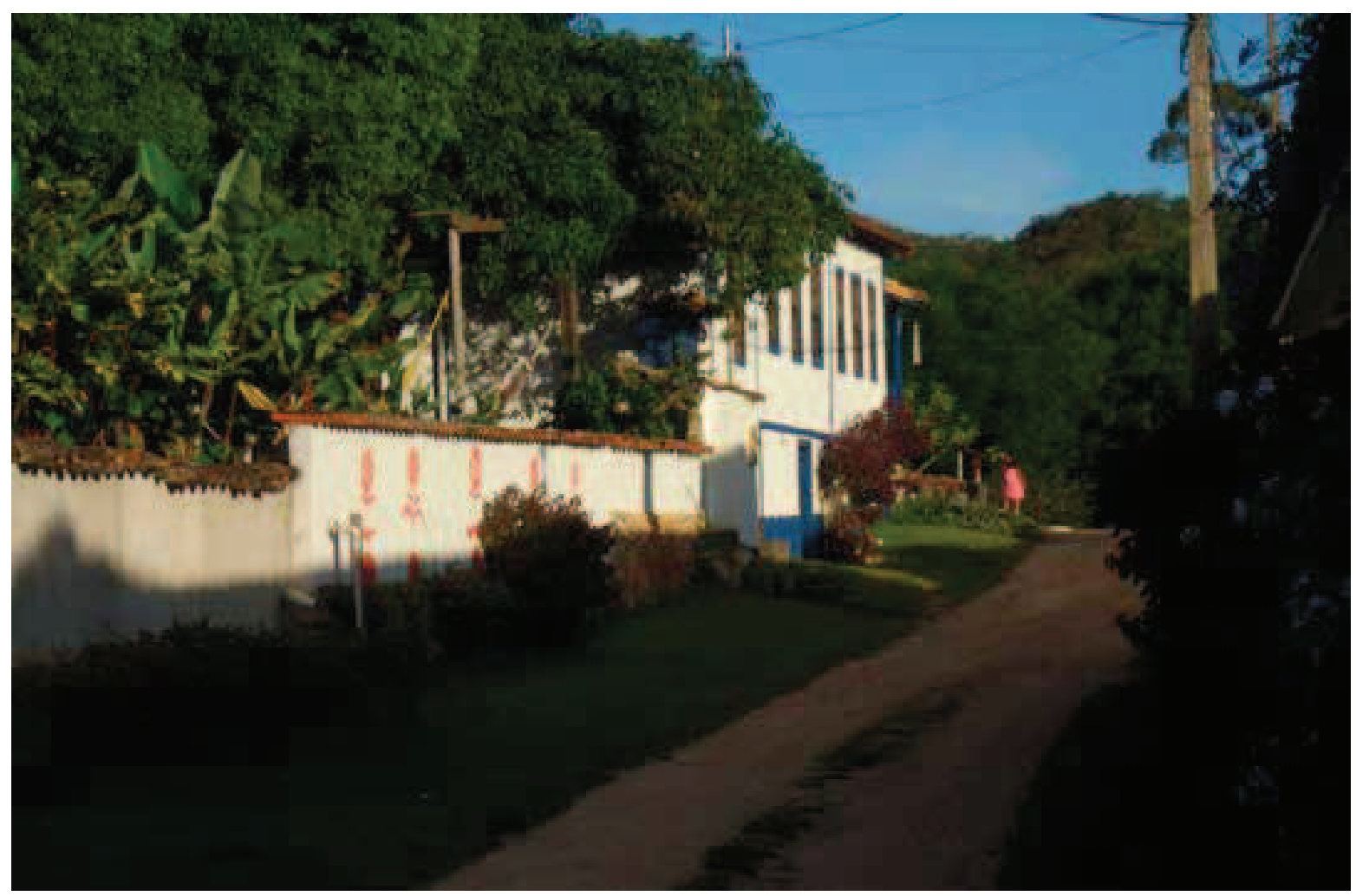

Figura 10 Muro de embasamento de pedras e parede de alvenaria rebocada e caiada. Foto: Altamiro Sérgio Mol Bessa - 2010.

\section{AS FORÇAS QUE CONSTROEM AS PAISAGENS TURÍSTICAS}

As forças verticais ${ }^{5}$ resultam de projetos e/ou ações comandados de fora dos territórios e são capazes de determinar ações internas, que se processarão nas paisagens, resultando em sua alteração. Impõem-se, através de ações planejadas, intenções de organização dos territórios. Em Milho Verde e São Gonçalo, estas verticalidades impuseram-se, com muita força, em dois momentos: no primeiro, através da Demarcação Diamantina; no segundo, iniciado no final do século $X X$, dura até os dias atuais, imposto pelo turismo.

Nas paisagens de Milho Verde, as forças verticais incidentes do período da dominação portuguesa até meados da década de 1980 encontraram pouca resistência das forças locais, por duas razões principais:

a) no período da dominação portuguesa, qualquer tentativa de organização de reações locais era duramente reprimida;

b) depois, a concentração de terras nas mãos de poucos proprietários, a existência de um poder político local conservador e oligárquico, o baixo nível de

5 As forcas verticais são aquelas impostas aos lugares por processos econômicos, empresas ou organizações, tais como a Fédération Internationale de Football Association (FIFA) e o Comitê Olímpico Internacional (COI), que passam a ditar as regras àqueles territórios. Para Santos (2004, p. 106), nas verticalidades, "[...] decisões essenciais concernentes aos processos locais são estranhas ao lugar e obedecem a motivações distantes." Segundo o autor, ao contrário das verticalidades, as horizontalidades constituem o conjunto das forças locais, nascidas da organização comunitária e que têm no seu próprio espaço geográfico a origem das atividades produtivas. 
instrução da população e sua dispersão nas zonas rurais, a falta de intercâmbio cultural e a dependência das atividades econômicas agropastoris não possibilitaram a constituição de forças locais articuladas e coesas que pudessem oferecer algum tipo de reação organizada às verticalidades.

Em São Gonçalo, as forças verticais incidentes do período colonial às décadas finais do século XX, embora da mesma natureza das incidentes em Milho Verde, encontraram maiores resistências das forças locais. Estas resistências puderam constituir-se:

a) pela maior presença de estrangeiros nos seus territórios, principalmente de europeus que traziam não só a sua cultura, mas também inovações tecnológicas e novas ideias políticas;

b) pela existência de um poder político liberal, contrário ao poder político conservador dominado pelas elites do Serro, o que criou uma força opositora aos conservadores valores monarquistas;

c) pelo fato de a localidade ter se transformado num entreposto comercial, aberta, portanto, a trocas econômicas e culturais mais frequentes;

d) pelo desenvolvimento de alternativas produtivas à mineração, tais como a indústria vinícola, as lapidações e a fabricação de doces, o que fez com que a localidade, após o declínio da mineração, ainda mantivesse sua economia em algum funcionamento;

e) pela maior presença da população na área urbana, favorecendo a constituição de grupos sociais e trocas cotidianas;

f) pela proximidade política e cultural de Diamantina, cidade vanguardista que capitaneou o processo de industrialização mineiro; esta proximidade fazia chegar a São Gonçalo novos valores e ideias.

Por pouco mais de um século, de 1860 a 1980, as forças verticais incidentes sobre os Distritos de Milho Verde e São Gonçalo diminuíram muito de intensidade, uma vez que, com o declínio da mineração de ouro e diamantes, desapareceu o interesse das firmas, que se retiraram daquelas paisagens, em explorar aquelas áreas. Ao se retirarem, deixaram heranças não só nos sistemas de objetos, como edificações, caminhos, equipamentos, mas também nos de ações, expressas por técnicas, fazeres, hábitos e tradições. Muitas destas heranças são hoje apropriadas pelo turismo.

Os discursos do projeto Estrada Real somaram-se às forças verticais, que passaram a incidir nos territórios estudados, trazidas pelo turismo a partir das últimas décadas do século XX, explorando os recursos naturais e o patrimônio cultural, que se manteve relativamente preservado pelo abandono que tomou conta de todo o norte mineiro. Em Milho Verde, as novas forças verticais incidentes produziram paisagens tendendo para a insustentabilidade e, em São Gonçalo, à sustentabilidade.

Das experiências de Milho Verde e São Gonçalo verifica-se que as mesmas forças verticais incidentes podem produzir resultados negativos e/ou positivos sobre as paisagens, e que não basta apenas a incidência destas forças nas paisagens para que 
estes resultados ocorram. Será sempre necessário que as forças verticais se confrontem com as forças locais.

Ao descrever as forças verticais incidentes em Milho Verde e São Gonçalo, sempre apareciam forças locais, movimentos associados aos próprios lugares. Estes movimentos, organizados ou não, constituem uma forma de resistência à chegada de forças externas. A cada nova verticalidade incidente, novas forças locais posicionam-se.

Forças locais existem em qualquer território onde haja pessoas. Cada indivíduo, em sua relação com os outros e com o meio, é uma força local, aqui chamada horizontal. Em dado momento, estes indivíduos, organizados para interesses comuns, podem reagir coletivamente, constituindo um conjunto de forças locais: as horizontalidades. Assim, horizontalidades são um conjunto de forças horizontais agindo da mesma maneira com um ou mais objetivos comuns.

Mudando os interesses envolvidos, as forças reagrupam-se e antigas horizontalidades se desfazem ou mudam e/ou novas se constituem. Assim, horizontalidades são organizações de forças provisórias, contingentes.

As horizontalidades podem tender para fortes a fracas. $\bigcirc$ que dá intensidade às horizontalidades é a sua coesão, o grau de articulação e envolvimento das forças que as compõem. Em Milho Verde, por exemplo, as horizontalidades são fracas, por um conjunto de razões. Dentre as principais destacam-se:

a) muitos moradores parecem ter uma relação provisória com aquele território; só pensam em ir embora;

b) o baixo nível de escolaridade e informação de grande parte da população, que não consegue ter o entendimento da importância da sua participação na decisão dos destinos da sua comunidade;

c) a omissão, incapacidade ou falta de interesse dos adventícios em operar no sentido de construir horizontalidades mais coesas, como o fez Martin em São Gonçalo;

d) a ação oportunista de outros adventícios, pessoas de fora de Milho Verde ou moradores que se aproveitam da ausência de coesão das horizontalidades locais e da omissão estatal, construindo onde querem e como querem, apropriando-se das melhores vistas e localizações;

e) a ausência do poder municipal, que não cumpre suas funções constitucionais de planejar, gerir e controlar o uso e a ocupação do solo e outros serviços públicos.

Na interpretação dos dados desta pesquisa, observou-se que, além das verticalidades incidentes e das horizontalidades, outro grupo de forças atua nos territórios. A estas forças denomino "forças de filtro". Defino as forças de filtro como sendo aquelas que, não sendo verticais (que só podem ser comandadas de fora dos territórios) nem horizontais (que só podem ser comandadas dos territórios), são criadas por instâncias externas, valem para diversos territórios e podem ser controladas de fora ou de den- 
tro deles. Estas forças filtram a incidência das forças verticais ou horizontais, que, ao passarem por elas, diminuem ou aumentam a sua intensidade, materializando-se de outra maneira nas paisagens.

Assim, forças de filtro são legislações e ordenamentos públicos criados de fora dos territórios, que disciplinam ações e comportamentos que valem para diversas localidades. Elas podem modificar a ação das forças verticais e/ou horizontais, podendo ser acionadas tanto pelos macroatores, que comandam as verticalidades, quanto pelos atores, que comandam as forças horizontais.

Quando as forças de filtro são muito fortes, ou seja, existem legislações rigorosas, que disciplinam vários aspectos da vida dos territórios, e quando elas são mobilizadas por forças também coesas, verticais e/ou horizontais, tendem a funcionar como barreiras fortes, conformando o que aqui se denomina "filtro fechado", como acontece em São Gonçalo. Quando as forças de filtro são fracas, ou seja, as legislações são permissivas e pouco rigorosas, mesmo que mobilizadas por forças verticais e/ou horizontais coesas, tendem a produzir poucas alterações nas forças incidentes, tendendo a constituir o que aqui se denomina "filtro aberto", caso de Milho Verde.

\section{CONCLUSÃO}

A construção de paisagens turísticas passou a ocorrer com mais intensidade a partir dos anos 1970, na Europa e nos Estados Unidos, quando grandes cidades com rico patrimônio cultural, rotas históricas e pequenos núcleos medievais tornaram-se alvo da atividade turística. Estas primeiras experiências, europeias e americanas, somaram-se a outras, constituindo um conjunto de técnicas e processos de construção de paisagens turísticas que se espalharam por todo o mundo.

Nesta ação, os projetos turísticos escolhem formas, objetos e ações preexistentes, reorganizando-os de modo a satisfazer o imaginário de potenciais visitantes. Algumas das formas e dos objetos originais hoje apropriados pelo turismo foram construídos sobre um meio frágil, que não poderia recebê-los, e sofreram a incidência de atividades produtivas resultantes de práticas e ideologias que afirmavam a supremacia do lucro, do particular sobre o coletivo, e que terminaram por produzir muitas inadequações. Este é o caso de vários núcleos e rotas históricas brasileiras nascidas como resultado dos empreendimentos mercantis criados pela Coroa Portuguesa a partir do descobrimento das terras brasileiras, e que hoje estão sendo submetidas às verticalidades do turismo.

As primeiras verticalidades incidentes em Milho Verde resultaram de uma exploração mineral estatal que negava as paisagens locais: rios, matas, campos de cerrado, nada importava - apenas o ouro e os diamantes, que, extraídos com precárias técnicas, produziram extraordinária devastação. Neste enclave da destruição, forças de filtro autoritárias ajudaram a garantir a supremacia dos processos insustentáveis. Os aventureiros, atraídos por estas verticalidades, estabeleceram com o território uma relação primeira de sobrevivência imediata, e construíram ocupações que foram se espraiando em direção ao frágil ambiente circundante. Nestas paisagens, onde tudo 
parecia provisório, prevaleciam sobre os aspectos estéticos os aspectos técnicos da ação humana predatória.

histórico de Milho Verde revela que os processos produtivos sempre foram incompatíveis com as potencialidades do seu meio ecológico, contribuindo muito para a insustentabilidade das suas paisagens atuais. Estes tão violentos processos históricos de construção de incapacidades deixaram marcas na forma como as sociedades locais que se seguiram relacionavam-se com o espaço geográfico e seus recursos. Estas sociedades aprenderam a priorizar o que é instantaneamente necessário: escavar leitos de rios e encostas para encontrar pedras preciosas; retirar a vegetação, através de queimadas, para plantar; cortar inadequadamente o terreno para construir; encaminhar as águas servidas para os córregos; ocupar divisores de água, fundos de vale e áreas de preservação. $\bigcirc$ homem comum de Milho Verde não aprendeu e, portanto, não sabe conciliar técnica e estética. Esta atitude de desprezo para com a natureza e tudo o que ela pode oferecer, aliada à omissão estatal, reflete-se nos espaços livres, que desde a fundação da localidade até os dias atuais são descuidados e abandonados, pois estiveram sempre na conta de áreas de reserva para a expansão do modelo predatório de exploração econômica.

Por outro lado, há lugares que, se não nasceram compatíveis com os recursos dos seus territórios, aprenderam a empregar técnicas adequadas às suas fragilidades. Em São Gonçalo, desde o início os habitantes conheceram, devido a estrangeiros e funcionários qualificados da Coroa que ali passaram a residir, técnicas que possibilitaram uma relação menos agressiva com a natureza. As paisagens da localidade, ao fim da mineração, já exprimiam os cuidados com o ordenamento territorial, a qualidade das edificações e a preservação ambiental, prestados por uma comunidade, iá àquela época, organizada. Não tendo terras férteis no seu entorno, os quintais das casas foram transformados em pequenas chácaras. Os quintais, para além da função utilitária, criaram um conjunto paisagístico cujo resultado foi um todo harmônico, com as edificações, as áreas livres, as encostas e o rio, que se manteve limpo. Nas paisagens diamantinas, o aspecto estético prevalecia sobre o técnico. As atividades que seguiram ao declínio da mineração basearam-se na exploração racional de antigos recursos, já instalados no território: doces de frutas dos quintais - como a uva, que também produziu vinhos -, artesanato de capim e tapetes. Esta nova sobreposição de processos de estruturação econômica de bases sustentáveis apoiou-se em unidades territoriais de alta qualidade paisagística. Há, até a chegada do turismo, processos compatíveis com os recursos do lugar, refletidos em paisagens côncavas que tendiam à sustentabilidade, como previa uma das hipóteses deste trabalho.

O turismo que se implantou em Milho Verde retoma o antigo Caminho dos Diamantes não como atrativo turístico, mas como estrutura espacial que guia a maior parte dos processos insustentáveis em curso na localidade. Neste processo, novas degradações ambientais acrescentam-se às antigas, tais como a ocupação de encostas, a destruição dos quintais e do patrimônio histórico, a construção em áreas de preservação, a polvição visual e sonora e dos cursos d'água. Novamente, nas paisagens 
contemporâneas de Milho Verde, predominam aspectos técnicos degradantes sobre os qualificadores dos territórios e sobre os aspectos estéticos. As estruturas do passado serviam às verticalidades da mineração, e as de hoje, novas ou reapropriadas, ao turismo. Atualmente em Milho Verde as forças de filtro não conseguem ser acionadas pelas horizontalidades.

O tipo de turismo que se estabeleceu em São Gonçalo recupera as capacidades que deram ao lugar boa qualidade paisagística no passado, reorganizando-as e/ou modernizando-as. Este turismo não só conserva o aprazível conjunto paisagístico e arquitetônico, mas produz outros, inserindo novas estruturas em harmonia com o ambiente. $O$ turismo em São Gonçalo insere mudanças sobre as paisagens que continuam a garantir-lhes a qualidade. A atividade retoma, assim, a capacidade sempre presente no lugar de relacionar-se com a natureza de forma sustentável. $\bigcirc$ mesmo turismo atrai estrangeiros, mobilizadores e criadores de horizontalidades positivas, como no passado, o que reedita e potencializa a ação dos atores locais de organizar e gerir os espaços públicos. Incapacidades também são retomadas em São Gonçalo, mas são superadas pelas capacidades recuperadas.

As evidências encontradas nesta pesquisa apontam para o fato de que o novo, ao ajustar-se ao existente, faz aflorar aquilo que ao longo dos tempos foi dando forma e sentido às paisagens e que nelas permanecem presentes. A construção das paisagens turísticas, ao tomar objetos e ações preexistentes que interessam aos turistas, dá aos mesmos novos arranjos, introduzindo elementos de fora do lugar. Os conflitos decorrentes desta superposição de novidades sobre o antigo, do embate entre verticalidades e horizontalidades, somam-se aos conflitos antigos, que ali permanecem presentes, fazendo reviver muitos deles.

Dependendo do tipo de turismo que se implanta nos lugares, pode haver supressão de direitos, principalmente quando se destina o melhor dos espaços coletivos aos turistas ou quando se faz uma ordenação excessiva destes espaços, levando a vida cotidiana para o interior dos espaços privados. Esta supressão dar-se-á com mais força nos lugares onde isto já acontecia no passado. Por outro lado, determinado tipo de turismo, mais qualificado, pode encorajar novas formas de superação de injustiças, de reestruturação econômica e resolução de conflitos, principalmente quando incidir em lugares com tradição de participação dos atores locais no trabalho coletivo de construção social.

Em síntese, os resultados encontrados são a favor do argumento central deste trabalho: que o turismo, ao tentar retomar ocupações e traçados do passado, pode retomar, simultaneamente, (in)capacidades e conflitos presentes desde sempre nos lugares. 


\section{REFERÊNCIAS BIBLIOGRÁFICAS}

ARDNT, Jorge Renato Lacerda. Entre tradição e modernidade: sustentabilidade do desenvolvimento pelo turismo em uma comunidade tradicional de Minas Gerais. 2007. 332 f. Tese (Mestrado em Administração) - Faculdade de Estudos Administrativos de Minas Gerais, Centro de Gestão Empreendedora, Belo Horizonte, 2007.

MAWE, John. Viagem ao interior do Brasil principalmente aos distritos do ouro e dos diamantes [1812]. Rio de Janeiro: Zelio Valverde, 1944. 347 p.

MORAES, Fernanda Borges. De arraiais, vilas e caminhos: a rede urbana das minas coloniais. In: RESENDE, Maria Efigênia Lage de; VILLALTA, Luiz Carlos. (Orgs.). História de Minas Gerais: as Minas setecentistas, v. 1. Belo Horizonte: Autêntica, 2007, p. 55-85.

SANTIAGO, Luis. Serro: política, geografia e cultura, v. 3. Belo Horizonte: Edições Morada Santiago, 2006. 204 p.

SANTOS, Milton. Por uma outra globalização: do pensamento único à consciência universal. Rio de Janeiro: Record, 2004. 174 p. 